\title{
Nota Científica: Características físico-químicas e aceitação sensorial de hambúrguer de búfalo em comparação com hambúrguer bovino
}

\author{
Scientific Note: Physicochemical parameters and sensory acceptance of buffalo \\ burgers as compared to beef burgers
}

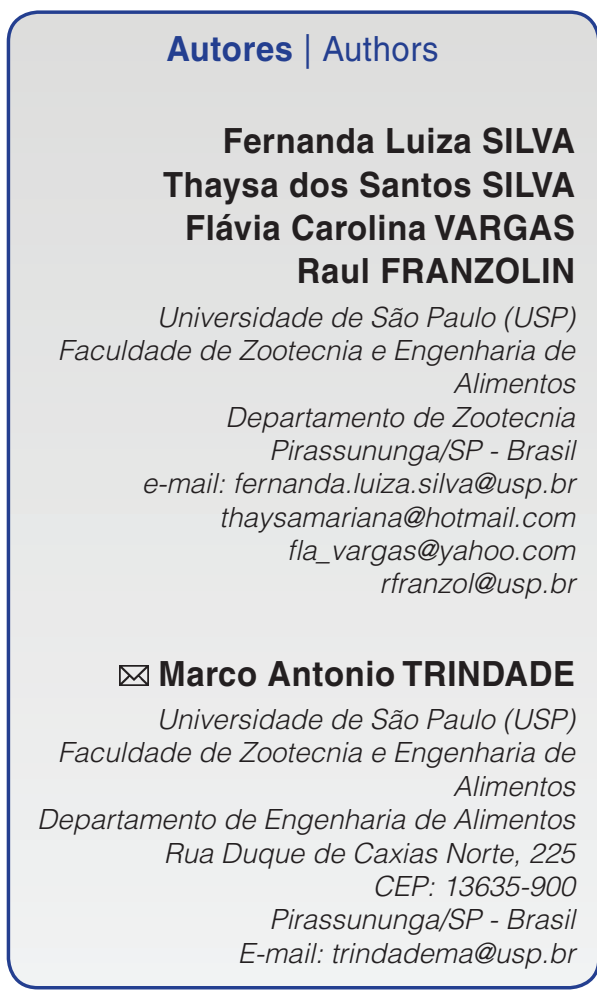

Autor Correspondente / Corresponding Author

Recebido: Maio 22, 2014

Aprovado: Jan. 15, 2015

\section{Resumo}

O propósito deste trabalho foi comparar parâmetros físico-químicos e sensoriais de hambúrgueres produzidos com carnes bovina ou bubalina, buscando alternativa para ampliar o consumo da carne de búfalos. Foram realizadas análises físico-químicas de composição centesimal (teores de proteína, umidade, gordura e cinzas), valor de $\mathrm{pH}$, cor objetiva $\left(\mathrm{L}^{*}, \mathrm{a}^{*} \mathrm{e} \mathrm{b}^{*}\right)$, força de cisalhamento, perdas por cocção e redução de diâmetro (encolhimento). A aceitação sensorial foi avaliada por testes de aceitação utilizando-se escala hedônica de nove pontos para os atributos aparência, textura, suculência, sabor e qualidade global. Em relação à composição centesimal, as duas formulações apresentaram teores de umidade próximos a $65 \%, 1 \%$ de cinzas, $17 \%$ de proteínas e $13 \%$ de lipídeos. Não foram encontradas diferenças $(\mathrm{p}>0,05)$ para os valores de $\mathrm{pH}(5,49-5,50)$, força de cisalhamento $(0,62-0,86 \mathrm{kgf})$, perdas por cocção $(23,04-29,40 \%)$ e redução de diâmetro (16,40-20,29\%). As análises de cor também não diferiram ( $p>0,05)$ entre as amostras, com valores médios próximos a 8, 4 e 10 para os parâmetros $L^{*}$, a* e $b^{*}$, respectivamente. Com relação à análise sensorial observou-se diferença estatística $(p<0,05)$ apenas no atributo suculência, no qual o hambúrguer bovino $(7,63)$ foi superior ao bubalino $(7,17)$. Para os demais atributos avaliados não foram verificadas diferenças significativas $(p>0,05)$ na aceitação pelos consumidores, que atribuíram notas na faixa de 7 (gostei moderadamente) a 8 (gostei muito). Pode-se concluir que o hambúrguer de carne bubalina apresenta parâmetros tecnológicos e aceitação sensorial similares ao hambúrguer de carne bovina, podendo portanto representar uma boa alternativa para ampliação do consumo da carne de búfalo.

Palavras-chave: Búfalo; Produto cárneo; Composição; Aceitação sensorial.

\section{Summary}

The purpose of this research was to compare the physicochemical and sensory parameters of hamburgers made with bovine and bubaline meats, aiming to find alternatives to increase the consumption of buffalo meat. The physicochemical analyses included the proximate composition (protein, moisture, fat and ash), $\mathrm{pH}$ value, objective colour ( $\mathrm{L}^{*}, \mathrm{a}^{*}$ and $\left.\mathrm{b}^{*}\right)$, shear force, cooking loss and shrinkage. The sensory acceptance was accessed using an acceptance test with a ninepoint hedonic scale for the following attributes: appearance, texture, juiciness, flavour and overall quality. Regarding the proximate composition, both formulations presented similar values for moisture, ash, protein and lipids (approximately 65\%, $1 \%, 17 \%$ and $13 \%$, respectively). No differences were found for the $\mathrm{pH}$ values (5.49-5.50), shear force (0.62-0.86kgf), cooking loss (23.04-29.4\%) or shrinkage $(16.4-20.29 \%)$ ( $p>0.05)$. The colour analyses did not differ ( $p>0.05)$ between the samples, with mean values of around 8,4 and 10 for the parameters of $L^{*}, a^{*}$, and $b^{*}$, respectively. Concerning the sensory analysis, a statistical difference $(p<0.05)$ was only found for the attribute of juiciness, where the bovine hamburgers (7.63) were superior to the bubaline ones (7.17). For the other attributes, no statistical differences ( $p>0.05$ ) were found by the consumers, who awarded scores of 7 (like moderately) and 8 (like very much). It was concluded that, in comparison with hamburgers made from beef meat, hamburgers made from buffalo meat showed similar technological parameters and sensory acceptance, representing a good alternative to increase the consumption of this meat.

Key words: Buffalo; Meat product; Composition; Sensory acceptance. 


\section{Introdução}

O búfalo (Bubalus bubalis) foi domesticado entre 2.500 e 1.400 a.C. no continente asiático e, desde então, vem sendo cada vez mais utilizado pelo homem por sua característica de tripla aptidão (corte, leite e trabalho) (COCKRILL, 1984). O Brasil possui o maior rebanho de búfalos das Américas (JORGE et al., 2011), com cerca de 1,2 milhão de animais, sendo a maior parte encontrada na Região Norte do país (IBGE, 2012).

Em pesquisa realizada por Velloso et al. (1994), os bubalinos apresentaram melhor conversão alimentar para forrageiras, além de melhor ganho de peso e maior precocidade em relação aos bovinos Nelore, o que torna a espécie muito interessante para a terminação em confinamento.

Apesar de apresentar algumas vantagens quando comparada à bovina, a carne bubalina ainda não possui um padrão de identidade e qualidade definido (JORGE, 2004) e por isso é geralmente comercializada como carne bovina (OLIVEIRA, 2005). Semelhanças no que diz respeito aos parâmetros físico-químicos (teor de umidade, proteínas, minerais, pH e perda por cocção) e sensoriais (suculência, sabor, aroma, maciez, textura e cor) foram reportadas por alguns autores, assim como diferenças em relação ao teor de gordura e força de cisalhamento, para os quais a carne de bubalinos apresenta valores menores (OHLY, 1997; MERLE et al., 2004; RODRIGUES; ANDRADE, 2004).

No Brasil e no mundo é crescente a demanda por alimentos de preparo fácil e rápido, devido ao atual modo de vida urbano (GARCIA, 2003). Nesse contexto, destacam-se os hambúrgueres, consumidos em grande quantidade (GALÁN et al., 2010) pela praticidade de preparo, variedade de apresentação comercial e ampla faixa de preço nos mercados (PAULINO, 2012). A utilização da carne bubalina em produtos cárneos processados, mais especificamente em hambúrgueres, poderia representar uma forma de ampliar a aceitação desse tipo de carne pela população.

Diante do exposto, o presente estudo teve por objetivo avaliar e comparar parâmetros físico-químicos e a aceitação sensorial de hambúrgueres produzidos com carne bubalina e com carne bovina, buscando-se uma possível alternativa para ampliar o consumo da carne de búfalos.

\section{Material e métodos}

\subsection{Material}

Para obtenção das amostras foram utilizados os cortes patinho e paleta, cujos componentes musculares estão descritos na portaria n. 5 , de 8 de novembro de 1988, do Ministério da Agricultura, Pecuária e Abastecimento (BRASIL, 1988), a qual aprova a padronização dos cortes de carne bovina. Os músculos utilizados foram provenientes de um animal bovino Nelore castrado (Bos indicus indicus, 2 anos, $526 \mathrm{~kg}$ de peso vivo) e de um bubalino Mediterrâneo castrado (Bubalus bubalis, 2 anos, $439 \mathrm{~kg}$ de peso vivo), ambos abatidos no matadouro-escola do campus da USP de Pirassununga, de acordo com o Regulamento de Inspeção Industrial e Sanitária de Produtos de Origem Animal (BRASIL, 1952). Os músculos que compõem os cortes da paleta e do patinho, juntamente com a gordura subcutânea da carcaça de cada animal, foram separados e armazenados em freezer $\left(-18^{\circ} \mathrm{C}\right)$, até a produção dos hambúrgueres. A quantidade dos ingredientes utilizados para a elaboração dos hambúrgueres encontra-se na Tabela 1. A carne e a gordura, após descongeladas, foram moídas (discos de $4 \mathrm{~mm}$ ), pesadas e acrescidas dos demais ingredientes. Após a homogeneização (10 minutos), a mistura foi submetida à prensagem e moldagem em formatadora manual (Picelli, Hp112, $11 \mathrm{~cm}$ de diâmetro). Os hambúrgueres obtidos (100 unidades de cada espécie, pesando entre $95 \mathrm{~g}$ e $100 \mathrm{~g}$ ) foram acondicionados em papel manteiga, identificados, congelados em congelador ultrarrápido (UCE - 20, ECO) e novamente armazenados em freezer $\left(-18^{\circ} \mathrm{C}\right)$.

Este trabalho foi realizado na Faculdade de Zootecnia e Engenharia de Alimentos da Universidade de São Paulo, Campus de Pirassununga, São Paulo, Brasil.

\subsection{Métodos}

\subsubsection{Determinações físico-químicas}

A determinação da composição centesimal (umidade, material mineral, proteína bruta e extrato

Tabela 1. Formulação utilizada para elaboração dos hambúrgueres bovino e bubalino.

\begin{tabular}{|c|c|c|}
\hline Ingredientes & $(\%)$ & Peso (kg) \\
\hline Carne & 78 & 7,80 \\
\hline Gordura & 14 & 1,40 \\
\hline Sal & 1,4 & 0,14 \\
\hline Condimento para hambúrguer sabor picanha & 1,5 & 0,15 \\
\hline Emulsificante (polifosfatos) & 0,3 & 0,03 \\
\hline Água & 4,8 & 0,48 \\
\hline Total & 100 & 10 \\
\hline
\end{tabular}


etéreo) foi realizada de acordo Silva e Queiroz (2002). Para as análises de perda de peso por cocção (PPC), os hambúrgueres congelados foram pesados e fritos em chapa industrial $\left(170^{\circ} \mathrm{C}\right.$ ) por seis minutos (três minutos cada lado), resfriados a temperatura ambiente e pesados novamente (três replicatas). A PPC foi determinada pela diferença de peso antes e após a cocção, dividida pela massa do hambúrguer cru multiplicada por 100. Para a determinação de redução de diâmetro (RD), mediu-se o diâmetro em três pontos nos hambúrgueres ainda crus e congelados. Em seguida os mesmos hambúrgueres foram fritos conforme descrito na análise de PPC, sendo as medições repetidas após o resfriamento à temperatura ambiente. O encolhimento (RD) foi determinado pelas diferenças de diâmetro antes e após a cocção, dividida pelo diâmetro do hambúrguer cru e multiplicada por 100. As medidas de força de cisalhamento (FC) foram realizadas com um equipamento Warner Bratzler modelo 235 6x, marca Salter Brecknell, com velocidade 200 mm/ min, cortando-se 10 retângulos de $1 \mathrm{~cm} \times 2 \mathrm{~cm}$ em três hambúrgueres de cada tratamento. A análise de $\mathrm{pH}$ nas amostras experimentais foi realizada utilizando-se pHmetro portátil (modelo HI99163, marca HANNA) com eletrodo combinado para leitura em triplicata de cada tratamento. As medidas de cor da carne foram realizadas utilizando-se um colorímetro (mod. MiniScan XE, marca HunterLab), baseando-se nos parâmetros $L^{*}, a^{*}, b^{*}$, do sistema Cielab, utilizando-se iluminante $D_{65}$, ângulo de observação de $10^{\circ}$ e abertura de célula com $30 \mathrm{~mm}$ para cálculo dos valores médios de 10 leituras.

\subsubsection{Análise sensorial}

Os hambúrgueres foram fritos como descrito na análise de PPC. Foi aplicado um teste de aceitação para os atributos: aparência, textura, suculência, sabor e qualidade global, com escala hedônica de 9 pontos (sendo: 1 detestei e 9 adorei), a 60 provadores não treinados (alunos, funcionários e professores), consumidores regulares de hambúrguer bovino. Cada julgador recebeu aproximadamente $16 \mathrm{~g}$ de cada tipo de hambúrguer em copinhos plásticos codificados com três dígitos aleatórios, conforme preconizado por Meilgaard et al. (1999). A limpeza das papilas gustativas entre as amostras foi realizada com água e bolacha de água e sal.

\subsubsection{Análises estatísticas}

Os resultados obtidos foram analisados por ANOVA em delineamento inteiramente casualizado, aplicando-se o teste de Tukey com 5\% de significância (SAS 9.2 for Windows).

\section{Resultados e discussão}

Os resultados da composição centesimal (Tabela 2) apresentaram diferença significativa apenas para os parâmetros Matéria mineral e Extrato etéreo, sendo superiores para o hambúrguer elaborado com carne bovina.

É importante ressaltar que com esses resultados os produtos atenderam aos padrões estabelecidos pela legislação brasileira que estabelece, segundo o Regulamento Técnico de Identidade e Qualidade de Hambúrguer (BRASIL, 2000), que essa classe de produtos deve conter no máximo 23\% de lipídios e no mínimo 15\% de proteínas. Rodrigues e Andrade (2004) encontraram valores semelhantes na composição das carnes bubalina e bovina para os teores de umidade $(73,7 \%$ vs. $71,7 \%)$, proteína ( $84,4 \%$ vs. $82,6 \%$ ) e minerais (4,29\% vs, 3,89\%), porém menor $(p<0,05)$ teor de gordura da carne bubalina $(10,8 \%)$ em relação à carne bovina $(15,4 \%)$.

Não foram observadas diferenças significativas entre os hambúrgueres de carne bovina e bubalina para perda por cocção, redução de diâmetro, força de cisalhamento e pH (Tabela 3). Rodrigues e Andrade (2004) obtiveram PPC de carne bovina e bubalina com variações entre $30,7 \%$ a $32,7 \%$, não se caracterizando diferença estatística, conforme observado no presente estudo. Da mesma forma, Hautrive et al. (2008) relatam um valor de 30,8 para PPC em hambúrgueres bovinos.

Tabela 2. Composição centesimal dos hambúrgueres bovino e bubalino.

\begin{tabular}{ccccc} 
Hambúrguer & Umidade (\%) & Matéria mineral $(\%)$ & Proteína bruta (\%) & Extrato etéreo (\%) \\
\hline Bovino & $65,47^{\mathrm{a}}$ & $1,11^{\mathrm{a}}$ & $17,38^{\mathrm{a}}$ & $13,66^{\mathrm{a}}$ \\
Bubalino & $65,58^{\mathrm{a}}$ & $1,08^{\mathrm{b}}$ & $17,78^{\mathrm{a}}$ & $12,54^{\mathrm{b}}$ \\
\hline
\end{tabular}

Médias seguidas de letras iguais, na mesma linha, não diferem entre si pelo teste de Tukey $(p<0,05)$.

Tabela 3. Perda de peso na cocção (PPC), encolhimento (RD), força de cisalhamento (FC) e pH das amostras de hambúrgueres.

\begin{tabular}{lccc} 
& Parâmetros & Hambúrguer bovino & Hambúrguer bubalino \\
PPC (\%) & $29,40^{\mathrm{a}} \pm 1,15$ & $23,04^{\mathrm{a}} \pm 4,47$ \\
RD (\%) & $20,29^{\mathrm{a}} \pm 2,51$ & $16,4^{\mathrm{a}} \pm 2,16$ \\
FC (kgf) & $0,62^{\mathrm{a}} \pm 0,12$ & $0,86^{\mathrm{a}} \pm 0,15$ \\
PH & $5,50^{\mathrm{a}} \pm 0,09$ & $5,49^{\mathrm{a}} \pm 0,02$ \\
\hline
\end{tabular}

Médias seguidas de letras iguais, na mesma linha, não diferem entre si pelo teste de Tukey $(p<0,05)$. 
Tabela 4. Determinação instrumental da cor das amostras de hambúrgueres

\begin{tabular}{lcc}
\multicolumn{1}{c}{ Cor instrumental } & $\begin{array}{c}\text { Hambúrguer } \\
\text { bovino }\end{array}$ & $\begin{array}{c}\text { Hambúrguer } \\
\text { bubalino }\end{array}$ \\
\hline Luminosidade $\left(\mathrm{L}^{*}\right)$ & $8,29^{\mathrm{a}} \pm 0,42$ & $8,54^{\mathrm{a}} \pm 0,97$ \\
Coloração vermelha $\left(\mathrm{a}^{*}\right)$ & $3,46^{\mathrm{a}} \pm 0,19$ & $4,80^{\mathrm{a}} \pm 0,91$ \\
Coloração amarela $\left(\mathrm{b}^{\star}\right)$ & $11,28^{\mathrm{a}} \pm 0,71$ & $9,03^{\mathrm{a}} \pm 2,10$ \\
\hline
\end{tabular}

Médias seguidas de letras iguais na mesma linha não diferem entre si $(p<0,05)$.

Tabela 5. Resultados da avaliação sensorial das amostras de hambúrgueres.

\begin{tabular}{lcc}
\multicolumn{1}{c}{ Atributos } & $\begin{array}{c}\text { Hambúrguer } \\
\text { bovino }\end{array}$ & $\begin{array}{c}\text { Hambúrguer } \\
\text { bubalino }\end{array}$ \\
\hline Aparência & $6,85^{\mathrm{a}}$ & $7,03^{\mathrm{a}}$ \\
Textura & $7,00^{\mathrm{a}}$ & $6,72^{\mathrm{a}}$ \\
Suculência & $7,63^{\mathrm{a}}$ & $7,17^{\mathrm{b}}$ \\
Sabor & $7,75^{\mathrm{a}}$ & $7,37^{\mathrm{a}}$ \\
Qualidade global & $7,55^{\mathrm{a}}$ & $7,30^{\mathrm{a}}$ \\
\hline
\end{tabular}

Médias seguidas de letras iguais na mesma linha não diferem entre si pelo teste de Tukey $(p<0,05)$.

Apesar de Merle et al. (2004) ter reportado valor menor de FC para carne bubalina, assim como Rodrigues e Andrade (2004) (bubalinos: 3,75 kgf e bovinos Nelore: $5,9 \mathrm{kgf})$, no presente trabalho não foram observadas diferenças estatísticas para esse parâmetro em relação à utilização da carne cominuída para a elaboração dos hambúrgueres.

Embora diferenças encontradas com relação ao parâmetro pH, Andrighetto et al. (2008), ao analisarem diferentes períodos de confinamento de bubalinos, obteveram valores de $\mathrm{pH}$ da carne entre 5,5 e 5,52, próximos aos encontrados neste estudo. Rodrigues e Andrade (2004), avaliando diferença no pH entre grupos genéticos e condição sexual de bovinos e búfalos também encontraram valores próximos para ambas as espécies, variando de 5,42 a 5,66. Semelhantemente, Hautrive et al. (2008) encontraram valor de 5,63 para o pH de hambúrguer bovino. Malik e Sharma (2011), ao analisar o tempo de prateleira de carne de búfalo acondicionada em diferentes embalagens, encontrou valores de $\mathrm{pH}$ variando entre 4,9 a 5,3.

Com relação aos parâmetros de cor $L^{*}, a^{*} e b^{*}$ dos hambúrgueres não foram encontradas diferenças significativas entre os dois tipos de hambúrguer analisados (Tabela 4), diferentemente do relatado por Rodrigues e Andrade (2004), que observaram diferença na intensidade do amarelo na carne dos diferentes grupos genéticos ( 1,5 para Nelore e 0,78 para bubalinos Mediterrâneo). Os maiores valores de $b^{*}$ encontrados no presente trabalho $(9,03-11,28)$ quando comparados aos valores citados anteriormente para carne de búfalo (RODRIGUES; ANDRADE, 2004), devem-se provavelmente ao maior teor de gordura presente nos hambúrgueres.

De acordo com os resultados do teste de aceitação sensorial, não foram observadas diferenças estatísticas entre os hambúrgueres bovino e bubalino (Tabela 5), com exceção do atributo suculência, no qual o hambúrguer bovino foi mais suculento $(p<0,05)$, o que pode estar ligado ao maior teor de gordura observado em sua composição centesimal (Tabela 2). Müller et al. (1994), ao compararem a carne in natura de bovinos Charolês e búfalos Mediterrâneo também verificaram maior suculência e marmoreio (gordura entremeada) para os bovinos. Mattos et al. (1997), por sua vez, não encontraram diferença significativa para os parâmetros suculência e teor de gordura ao compararem a carne de búfalos das raças Mediterrâneo e Jafarabadi à de bovinos da raça Nelore.

Com base nos resultados da avaliação sensorial pode-se afirmar que os dois tipos de hambúrguer, tanto de carne bovina quanto de carne bubalina, foram bem aceitos, sendo que para todos os atributos avaliados os consumidores atribuíram notas sensoriais na faixa de 7 (gostei moderadamente) a 8 (gostei muito), numa escala de 1 a 9 . Essas pontuações elevadas para ambas as formulações sugerem que o hambúrguer de carne bubalina poderia ser bem aceito do ponto de vista sensorial.

\section{Conclusão}

O hambúrguer elaborado com carne de búfalo apresentou características tecnológicas muito similares ao hambúrguer de carne bovina, ambos apresentando elevada aceitação sensorial e atendendo aos parâmetros de composição estabelecidos pela legislação brasileira, permitindo, portanto, concluir que a carne bubalina também pode ser utilizada para a confecção desse produto sem comprometer os parâmetros tecnológicos, físico-químicos e a aceitabilidade por parte dos consumidores de hambúrguer de carne bovina.

\section{Referências}

ANDRIGHETTO, C.; JORGE, A. M.; ROÇA, R. O.; RODRIGUES, E.; BIANCHINI, W.; FRANCISCO, C. L. Características Físicoquímicas e Sensoriais da Carne de Bubalinos Murrah Abatidos em Diferentes Períodos de Confinamento. Revista Brasileira de Zootecnia, Botucatu, v. 37, n. 12, p. 2179-2184, 2008.

BRASIL. Ministério da Agricultura, Pecuária e Abastecimento. Portaria $n^{\circ} 5$, de 8 de novembro de 1988. Aprova a padronização dos cortes de carne bovina, proposta pela divisão de padronização e classificação de produtos de origem animal. Diário Oficial da República Federativa do Brasil, Poder Executivo, Brasília, DF, 18 nov. 1988, Seção 1, p. 22291. 
Características físico-químicas e aceitação sensorial de hambúrguer de búfalo em comparação com hambúrguer bovino SILVA, F. L. et al.

BRASIL. Ministério da Agricultura. Regulamento da Inspeção Industrial e Sanitária de Produtos de Origem Animal - RIISPOA. Rio de Janeiro, 1952.

BRASIL. Ministério da Agricultura. Secretaria de Defesa Agropecuária. Instrução Normativa $n^{\circ} 20$, de 31 de julho de 2000. Aprova os Regulamentos Técnicos de Identidade e Qualidade de Almôndega, de Apresuntado, de Fiambre, de Hamburguer, de Kibe, de Presunto Cozido e de Presunto. Diário Oficial da República Federativa do Brasil, Poder Executivo, Brasília, DF, 03 ago. 2000.

COCKRILL, W. R. Water Buffalo. In: MASON, I. L. (Ed.). Evolution of Domesticated Animais. New York: Longman Inc., 1984. p. 52-53.

GALÁN, I.; GARCIA, M. L.; SELGAS, M. D. Effects of Irradiation on Hamburgers Enriched with Folic Acid. Meat Science, Barking, v. 84, n. 3, p. 437-443, 2010.

GARCIA, R. W. D. Reflexos da Globalização na Cultura Alimentar: Considerações sobre as Mudanças na Alimentação Urbana. Revista de Nutrição, Campinas, v. 16, n. 4, p. 483-492, 2003.

HAUTRIVE, T. P.; OLIVEIRA, V. R.; SILVA, A. R. D.; TERRA, N. N.; CAMPAGNOL, P. C. B. Análise Físico-química e Sensorial de Hambúrguer Elaborado com Carne de Avestruz. Ciência e Tecnologia de Alimentos, Campinas, v. 28, p. 95-101, 2008. http://dx.doi.org/10.1590/S0101-20612008000500016

INSTITUTO BRASILEIRO DE GEOGRAFIA E ESTATÍSTICA - IBGE. Efetivo dos Rebanhos, por Tipo de Rebanho. Rio de Janeiro, 2012. Disponível em: <http://www.sidra.ibge.gov.br/bda/tabela/ protabl.asp?c=73\&z=t\&o=24\&i=P>. Acesso em: 10 jun. 2014.

JORGE, A. M. Programa de Qualidade na Produção de Carne de Búfalos. In: SIMPÓSIO DO NÚCLEO DE ESTUDOS EM BUBALINOCULTURA, 1., 2004, Rio de Janeiro. Anais... Rio de Janeiro: UFRRJ, 2004.

JORGE, A. M.; COUTO, A. G.; CRUDELI, G. A.; PATIÑO, E. M. Produção de Búfalas de Leite. Botucatu: FEPAF, 2011. 181 p.

MALIK, A. H.; SHARMA, B. D. Shelf Life Study of Hurdle Treated Ready-to-eat Spiced Buffalo Meat Product Stored at $30 \pm 3{ }^{\circ} \mathrm{C}$ for 7 Weeks Under Vacuum and Aerobic Packaging. Journal of Food Science and Technology, Mysore, v. 51, n. 5, p. 832-844, 2011. PMid:24803689. http://dx.doi.org/10.1007/s13197-0110592-9

MAtTos, J. C. A.; NOGUeiRA, J. R.; OliveirA, A. A. D. Comparison on Carcass, Meat Cuts and Some Meat Quality
Characteristics of Buffaloes and Zebu. In: WORLD BUFFALO CONGRESS, 5., 1997, Caserta. Proceedings... Caserta: FAO/ IBF, 1997. p. 442-446.

MEILGAARD, M.; CIVILLE, G. V.; CARR, B. T. Sensory Evaluation Techniques. 3. ed. New York: CRC Press, 1999. 354 p. http://dx.doi.org/10.1201/9781439832271

MERLE, S.; SENCLEER, J.; RODAS-GONZALEZ, A.; GONZALEZ, J.; MANSUTTI, D.; HUERTA-LEIDENZ, N. Comparación de Machos Enteros Búfalos de Agua (Bubalus bubalis) VS Vacunos Acebuados en Características al Sacrificio, de la Canal, Rendimiento Carnicero y Palatabilidad del Longissimus. Archivos Latinoamericanos de Producción Animal, Venezuela, v. 12, n. 3, p. 112-120, 2004.

MÜLLER, L.; AGUIRRE, L. F.; RESTLE, J.; PEROBELLI, Z. Carcass and Meat Quality of Cattle and Buffalo. In: WORLD BUFFALO CONGRESS, 4., 1994, São Paulo. Anais... São Paulo: FAO/FINEP, 1994. p. 130-132.

OHLY, J. J. Prova Organoléptica com Carnes Bubalinas e Bovinas de Animais Criados nas Pastagens de Várzeas da Amazônia Central. Acta Amazônica, Manaus, v. 27, n. 1, p. 33-42, 1997

OLIVEIRA, A. L. Búfalos: Produção, Qualidade de Carcaça e de Carne. Alguns Aspectos Quantitativos, Qualitativos e Nutricionais para Promoção do Melhoramento Genético. Revista Brasileira de Reprodução Animal, Belo Horizonte, v. 29, n. 2, p. 122-134, 2005

PAULINO, F. O. Produção e Características de Qualidade de Hambúrguer de Carne de Jacaré-do-pantanal (Caiman crocodilus yacare). 2012. 100 f. Tese (Doutorado em Processamento Tecnológico de Produtos de Origem Animal)Universidade Federal Fluminense, Niterói, 2012.

RODRIGUES, V. C.; ANDRADE, I. F. Características Físicoquímicas da Carne de Bubalinos e de Bovinos Castrados e Inteiros. Revista Brasileira de Zootecnia, Viçosa, v. 33, n. 6, p. 1839-1849, 2004.

SILVA, D. J.; QUEIROZ, A. C. Análise de Alimentos: Métodos Químicos e Biológicos. 3. ed. Viçosa: UFV, 2002. 235 p.

VELLOSO, L.; SCHALCH, E.; FRANZOLIN NETO, R.; ZANETTI, M. A. Desempenho Comparativo de Zebuínos Nelore e Bubalinos Mediterrâneos em Regime de Confinamento. Revista da Sociedade Brasileira de Zootecnia, Brasília, v. 23, n. 2, p. 236-241, 1994. 